\title{
Service Sector and Information Technologies: Development of New Opportunities
}

\author{
Aleksey Valeryevich Novikov, Deni Dokkaevich Saydulaev, Dinara Abdollovna Kremcheeva
}

\begin{abstract}
The aim of the article is to review information technology support of the functioning of the tourism services sector, identify unsolved problems and build an information system structure for modeling the infrastructure of the tourism services sector.For this purpose, an expert survey method was used to determine the current state of information technology application in the tourism services sector and characteristics of information support for modeling the tourism industry infrastructure.The article focuses on the existing software tools used in tourism, as well as unsolved problems and prospects of using information systems in the tourism business. It provides an overview of the current state of information support for the functioning of the tourism services sector. Information technologies have been structured, unsolved problems have been identified and methods of their solutions have been suggested.

Index Terms: information technologies, information system, geoinformation system, decision support system, cellular automaton.
\end{abstract}

\section{INTRODUCTION}

The tourism market is one of the most dynamic. Unlike other markets, it is characterized by a great number of participants, their significant geographic disconnection, rapid information update and intensive implementation of information technologies (IT) in the industry. Thus, in 2017, the total volume of sold tourism products exceeded 2.3 trn. US dollars, of which 935 bln. were spent through the Internet and 280 bln. US dollars - through mobile devices. In general, mobile sales showed exceptional growth, having raised from $2 \%$ share of the total sales volume in 2012 to $12 \%$ in 2017. Their share, according to forecasts, will reach $20 \%$ by 2022 [1].

Now, the development and existence of the tourism business in the services market is impossible without the implementation of state-of-the-art IT that ensure the quality of services, communication and data transfer, effectiveness of activity and improvement of service rate, as well as the ability to handle requests of each individual customer and ensure effective work in reverse direction [2].

The tourism sector is information rich as it is characterized by the diversity of business relations with partners, dynamic business processes, customization of tourism services, technological upgrade and high competitiveness. In this

Revised Manuscript Received on July 05, 2019.

Aleksey Valeryevich Novikov, Research Institute of the Federal Penitentiary Service of Russia, Moscow, Russia; Astrakhan State University, Astrakhan, Russia; Russian Customs Academy, Moscow, Russia.

Deni Dokkaevich Saydulaev, Chechen State University, Grozny, Russia.

Dinara Abdollovna Kremcheeva, Saint Petersburg Mining University, Saint Petersburg, Russia. regard, the development of the tourism business becomes impossible without the implementation of modern IT that ensure the following: integration and communication; improved quality of services; transfer of large amounts of information; higher service rate and activity effectiveness; ability to cater to the needs of each individual customer; effective feedback. In the practical activity of tourism companies, various types of IT are used.

Tourism activity is related to a great number of various data that have to be processed, filtered, searched for the most important and cleared of the unnecessary. The data flow is constantly increasing, and the problems are becoming more complex; therefore, the implementation and use of IT become a fundamental element of the activity of the tourism industry professionals and an important factor of success [3].

The use of modern IT in the tourism industry provides for the optimization of the behavior of the tourism market participants and the achievement of their goals. Data acquisition and processing methods enable higher effectiveness of the analysis and give the opportunity to consider the various impact and limitation factors and ensure management decision making in an uncertain environment.

Effective development of the tourism services sector depends on the implementation of modern IT. This applies to both the automation of operation of travel firms, hotels and personnel workplaces and the software for strategic planning and decision support in the tourism industry.

Today, there is a contradiction in the tourism industry between, on the one hand, a sufficiently developed mathematical apparatus for modeling the tourism industry processes, which helps to make scientifically grounded decisions, and, on the other hand, decisions in the tourism industry, which are made at the qualitative level. Addressing this contradiction requires the solution of an important scientific and applied problem, which is to create specialized information systems (IS), based on which a manager, investor or government institution will be able to make reasonable decisions on the selection of a building site, location of the elements of tourism infrastructure and strategy for the development of tourism and recreation systems. This determines the relevance of the research.

\section{LITERATURE REVIEW}

A great number of works of foreign researchers are dedicated to the application of state-of-the-art IT, in particular, geographic information systems (GIS) for forecasting and decision support in the tourism industry. 


\section{Service Sector and Information Technologies: Development of New Opportunities}

Thus, D. Geneletti [4] evaluated and compared the influence of the locations of potential ski resorts within the valleys of India, closely related to tourism. The method used in the work relies on the computation of spatial indicators using GIS for forecasting and qualitative determination of critical impacts, such as losses of ecosystem and fragmentation, soil erosion, geomorphological hazards, interference with the life of local flora and fauna. The multi-criteria analysis was employed to create comparative indexes and rank the ski resorts in accordance with their general suitability.

The work of J. A. Silberman and P. W. Rees [5] contains GIS model-based research, which identifies the most attractive settlements for the development of ski resorts in the Rocky Mountains, USA. Eighty-five operating resorts of the region were selected, each of which was evaluated according to four criteria: the seasonal amount of snow, potential skiing season, proximity to conservation areas and accessibility of human settlements, which can render services to skiers and vacationers. The results were used for all human settlements in the region of the Rocky Mountains and determined the potentially suitable ones to be reconstructed for ski resorts.

The work of Malaysian scientists [6] identified protected and compatible areas for tourism development using spatial modeling in GIS. The research describes a methodological approach based on GIS complex use and multi-criteria evaluation of decisions to establish nature protection and wetlands development priorities. A set of criteria for the evaluation of wetlands' biodiversity conservation and development was determined. Later these criteria were evaluated from the perspective of tourism conservation and development. Then, these criteria were weighted using the method of paired comparison multi-criteria evaluation and the results were integrated into a GIS. Several conservation scenarios were developed for the modeling of various evaluation perspectives. Generation and comparison of conservation and development scenarios highlighted the most important decision-making problems.

C.-H. Tsai, W.-C. Wang and C.-W. Chen [7] assessed the risks of Taiwan in the tourism industry. To build an evaluation model of a tourist region, the layering method and GIS that integrates information on emergency situations (spread of landfalls, mud streams, precipitations and typhoons, potential flooding maps) were used. Based on this information, a general map of natural hazards distribution was built. The module simplifies the decision-making process for builders in terms of selection of optimum sites for the construction of new tourist attractions and development of a strategy for the prevention of natural disasters.

Based on GIS, ESRI ArcView conducted research on retail sales in tourism and location of tourist attraction centers [8]. The value of GIS for general production costs and developers of travel destination points was demonstrated.

Thus, presently, the use of GIS for the needs of the tourism industry is a sufficiently developed practice. This issue is addressed by many studies, the basis of which is the use of GIS for the solution of specific, highly specialized problems. Much less frequently, GIS are employed for complex problems and integration with IS. Besides, a class of mathematical models exists and develops, which can be successfully used in the research of the characteristics of travel urbanized system, forecasting the development processes and effective land use. However, a pressing problem remains concerning the integration of models, methods and IT in a single IS, which can be effectively used for the tourism industry management.

\section{METHODS}

\section{A. General description}

To address the specified objectives, the expert survey method was employed to determine two main research problems:

1. current state of IT application in the tourism services sector;

2. prospects for the development of information support for modeling the infrastructure of the tourism industry.

Chief executives and senior management of travel agencies (26 experts in total) were involved in the expert survey.

\section{B. Algorithm}

During the expert survey, the experts were requested to evaluate and characterize the current state of IT application in the tourism services sector and propose the prospects for the development of information support for modeling the infrastructure of the tourism industry.

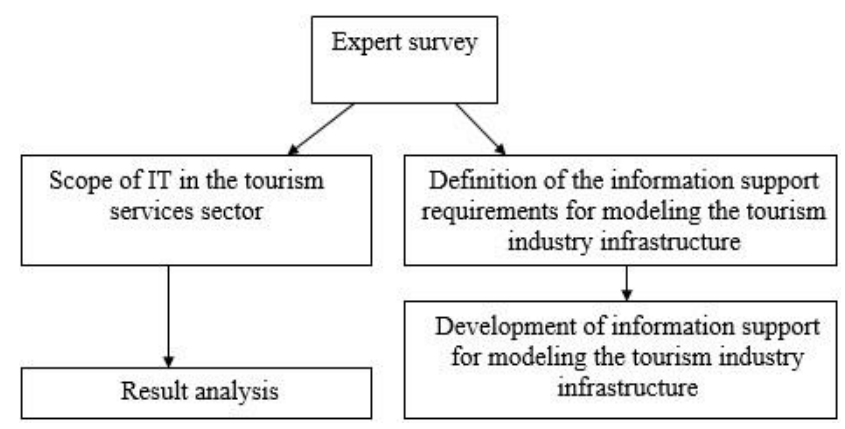

\section{RESULTS}

According to the experts, IT used in the tourism industry can be classified as follows (Table 1). 
Table 1. Scope of IT in the tourism services sector (according to the expert survey)

\begin{tabular}{|l|l|l|}
\hline № & Scope & Brief characteristics \\
\hline 1 & $\begin{array}{l}\text { automation of management } \\
\text { processes }\end{array}$ & personnel accounting, electronic document management, project management \\
\hline 2 & automation of accounting & $\begin{array}{l}\text { use of accounting software, specialized software for calculation of tour operators' } \\
\text { prices and flight loading management, opening of accounts in Internet money }\end{array}$ \\
\hline 3 & $\begin{array}{l}\text { collection and distribution of } \\
\text { information }\end{array}$ & $\begin{array}{l}\text { collection of tables, databases, development of catalogues, formation of data storages } \\
\text { and spaces }\end{array}$ \\
\hline 4 & Internet booking & $\begin{array}{l}\text { use of Internet booking systems on the company's websites, participation in } \\
\text { international Internet booking systems }\end{array}$ \\
\hline 5 & $\begin{array}{l}\text { marketing functions } \\
\text { development of nomenclature and production volumes of tourism services, pricing } \\
\text { policy, demand formation and sales management, marketing communications }\end{array}$ \\
\hline 6 & $\begin{array}{l}\text { forecasting and support of } \\
\text { decision-making }\end{array}$ & $\begin{array}{l}\text { use of spatial decision support system (SDSS), GIS and their add-ons, urbanization } \\
\text { modeling programs }\end{array}$ \\
\hline
\end{tabular}

More characteristics of the current state of IT application in the tourism services sector are provided below.

Thus, in the sphere of management automation, complex automation programs that ensure the effective functioning of a travel agency or travel operator, their communication, entry to global reservation and booking systems are involved. The tourism market offers the following software products: Master-Tour, Turwin Multipro, Parus-Touragency and others. These programs, as argued by one of the experts (Mikhail K., senior manager of a tourism company), "give an opportunity to form a tourism product, to prepare special offers with fixed and floating extra charges and discounts, to calculate expected profit of a tour and the rate of the agent's commission fee, to control information on agreements and their completion dates, to fill out tourists' documents, to print out price lists, package tours, lists of tourists, vouchers, forms for embassies and financial statements, to control the conduct of tours, to evaluate financial status of a travel firm and to create guide books with description of hotels, transportation, insurance conditions, visa support and extra services".

The most popular systems of hotel management automation, in the opinion of the experts, are Fidelio and Lodging Touch LIBICA. In addition, the Sinimex, Russian Hotel, Nevskiy Administrator, Edelweiss, In Style, B52®hotel, UCS Shelter, Interotel, etc. systems exist.

Management accounting systems are designed for the automation of a travel agency's business processes. They include the CRM class systems that enable online control over the office operation. The main software products in the tourism market, according to the experts, are Distant-Office, Turmate and Tour Manager CRM "CRM-solution" based on APEK-CRM Lite.

Oracle Data Integrator and DB2 Information Integration software are used for the collection and distribution of information. The experts note that these products are used in many spheres and are not specialized only for the needs of the tourism industry.

Internet booking systems provide air services, hotel accommodation services, information on whereabouts, weather conditions, currency rates, as well as bus and railway communication. According to the experts, the main systems are AMADEUS, Worldspan, Sabre and Galileo. Other global distribution systems include Trust, SRS (Steingerberger
Reservation Service) and Utell.

IT play an important role in the performance of marketing functions by the companies of the tourism industry because they simplify the solution of complex problems in a constantly changing dynamic business environment. IT ensure support of marketing in two main directions: by supplying the information necessary for marketing decisions and by providing the channels for rendering services in new ways [9].

The research gave us an opportunity to emphasize the following IT marketing functions: improvement of tourism product; communication policy; distribution of product and sales of marketing events.

Improvement of a tourism product at the level of a tourism company implies coordination of marketing efforts of providers of some tourism services, development of tour programs, pricing. The tourism services providers are the companies of the hospitality industry, transportation and insurance companies, sightseeing tour agencies, catering establishments, etc. Coordination of marketing efforts consists of the promotion of their product in the tourism services market.

The next marketing function implemented by tourism companies is communication policy. Advertisement tools on the Internet should include the following: banner ads on commercial sites; context ads in search systems; registration in search catalogues; optimization of websites for working in search systems; reach-media-advertising; commercial shows in the leading banner exchange networks; organization of text links exchange system; advertising by e-mail [10].

Forecasting and support of decision-making in the tourism industry are carried out using software products for urbanization modeling, GIS and their add-ons and spatial decision support systems (SDSS).

According to the experts, GIS allow for analysis, evaluation, forecasting and monitoring of tourism infrastructure, management of natural resources, as well as modeling and forecasting of the region portrait. One of the few GIS drawbacks is a built-in toolkit for data processing, which is fare worse than specialized mathematical packages in terms of features (MS Excel, Matlab, Maple, Mathcad, Mathematica, Statistica). 


\section{Service Sector and Information Technologies: Development of New Opportunities}

SDSS are computer systems designed to support users or groups of users in achieving the highest effectiveness of the decision-making process when solving partially structured spatial problems. These systems consist of DSS and GIS and are used to aid in spatial planning and guidance in land use decision making. Examples of SDSS are CommunityViz (spatial planning of buildings), Environment Explorer (environmental monitoring), LUMOCAP (agricultural land use evaluation) and Zer0-M (optimization of water flows in small settlements). Unfortunately, the expert survey showed a lack of specialized SDSS for tourism. The existing systems are not adapted for the solution of the tourism industry problems.

Software used for modeling of urbanization processes is a complex and multipurpose tool, which is employed in various sciences (urban science, geoinformatics, ecology, tourism). From the perspective of the tourism industry, as the experts believe, software products of such kind can be used to determine the attractiveness of territory, building sites or dynamics of settlement development, which will make it possible to make scientifically grounded management and investment decisions at different levels. Among the software tools for urbanization modeling, the experts distinguish the following: UrbanSim, LEAM, MOLAND and SLEUTH. These programs are designed for modeling of big cities, which is evidenced by a significant number of input parameters determining urbanization probability. Economic factors, transport, data on population, amenities, social sphere, neighboring types of land use and arbitrary factors are well-considered. Interrelated factors and the absence of some of these factors for small settlements will lead to incorrect determination of urbanization probability and ineffective modeling in general. For successful application of the programs, historical maps for several timeframes are needed as well. For small tourist towns, such data are often unavailable, many of them have been founded only recently and there are no informative changes in their structure, which is a weak point of the programs.

As the experts believe, the development of tourism in Russia requires a scientifically grounded decision making. Tourist spots are developed stochastically, and the infrastructure elements and building are placed without proper analysis of the attractiveness and effectiveness of the territory use. Managing and forecasting of these processes are important elements for successful development of tourism because they are related to the cost of land, investment, recreational flows and pricing policymaking.

The expert survey showed that the available IS do not allow for a comprehensive solution of this issue, even though it is relevant for local authorities, heads of tourism companies, managers and investors.

Meanwhile, the expert discussion of the prospects of information support development for modeling the tourism industry infrastructure made it possible to emphasize the following unsolved problems.

The absence of IS for modeling the infrastructure development processes for small tourist settlements. The available software products specialize in modeling the infrastructure of big cities developed according to the master plan. In turn, tourist settlements are developed stochastically, because the selection of the territory for infrastructure development depends on the choice made by people and investors. This determines the need for the development and application of IS, which will make it possible to study the spatial forms and infrastructure development of small tourist settlements, as well as the tourist attractiveness of these areas.

The presence of fragmented mathematical models of the spatial distribution of tourist settlement infrastructure provides the opportunity to solve modeling problems of tourism infrastructure development. The tourism industry is assigned to a class of a complex system. To investigate these systems, a multi-model approach is employed, because each of the models can describe only one system parameter. Normally, the models use similar input data, have advantages and disadvantages and are not automated. For the effective use of these models, it is necessary to further study the specifics of their application in the tourism industry, as well as automate and integrate them in a single IS [11].

Hence, the remaining problem is to develop the automation methods and, on these grounds, create an IS that would integrate the advantages of reviewed software products and be intended for forecasting of the tourism industry infrastructure. This will address the following practical problems: provide necessary information to local authorities, which deal with the planning of tourist settlement infrastructure development, alleviate the problem of selecting the prospective tourist facilities for investment and the tourism business.

Analysis of papers [12-14] showed that IS should consist of the following components: input data block, spatial distribution block of assigning the territory to urbanization, modeling and decision-making block.

The majority of software tools used for modeling and developing the infrastructure of big cities receive input parameters through GIS, which is a sufficient data source for calculations. GIS-technology unites digital processing of images, computer graphics with the database technology. This enables a researcher to perform a wide range of actions related to selection, processing, storage and analysis of information. Such technologies are distinguished by high flexibility and accessibility, which suggest high effectiveness of their application as IS components. In the proposed system, GIS is used to select the spatial data, form a training sample, pick infrastructure elements and show the modeling results.

Through GIS, a knowledge base is developed, using which the following computations are performed: definition of territory for placing new buildings, prices for land, infrastructure elements, calculation of investment attractiveness of the territory. The use of knowledge base makes it possible to receive more accurate results. Therefore, this component should be a part of an IS.

An automated program module of a mathematical model for tourism infrastructure forecasting is a necessary element of IS. The use of several mathematical models will enable modeling of various aspects of infrastructure and higher effectiveness of decision-making since different models have their advantages and disadvantages.

A mandatory parameter for many models is the level of territory suitability for

Published By: 
urbanization, which is computed based on two approaches. The first approach is built on the probability theory (calculation of spatial distributions of urbanization probabilities), the second one - on the use of fuzzy logic apparatus. Fuzzy logic-based calculations demonstrate the best results [15]; therefore, it is proposed to employ the module for building the spatial distributions of assigning the territory to an urbanized one. This will make it possible to automate the distribution building process and integrate the result in the model's program code as an input parameter.

Figure 1 presents an IS data flow context diagram (Data Flow Diagram). The following external entities exist for IS:
GIS (1), Matlab (2) and the user (3).

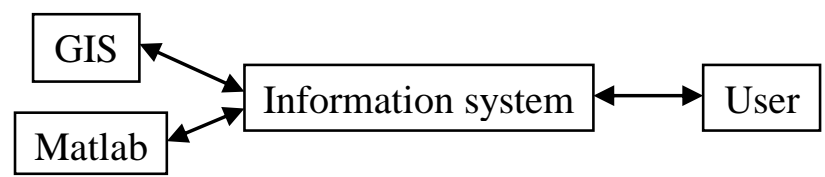

Fig. 1: IS data flow context diagram.

The structural chart of IS functioning should appear as shown in Figure 2.

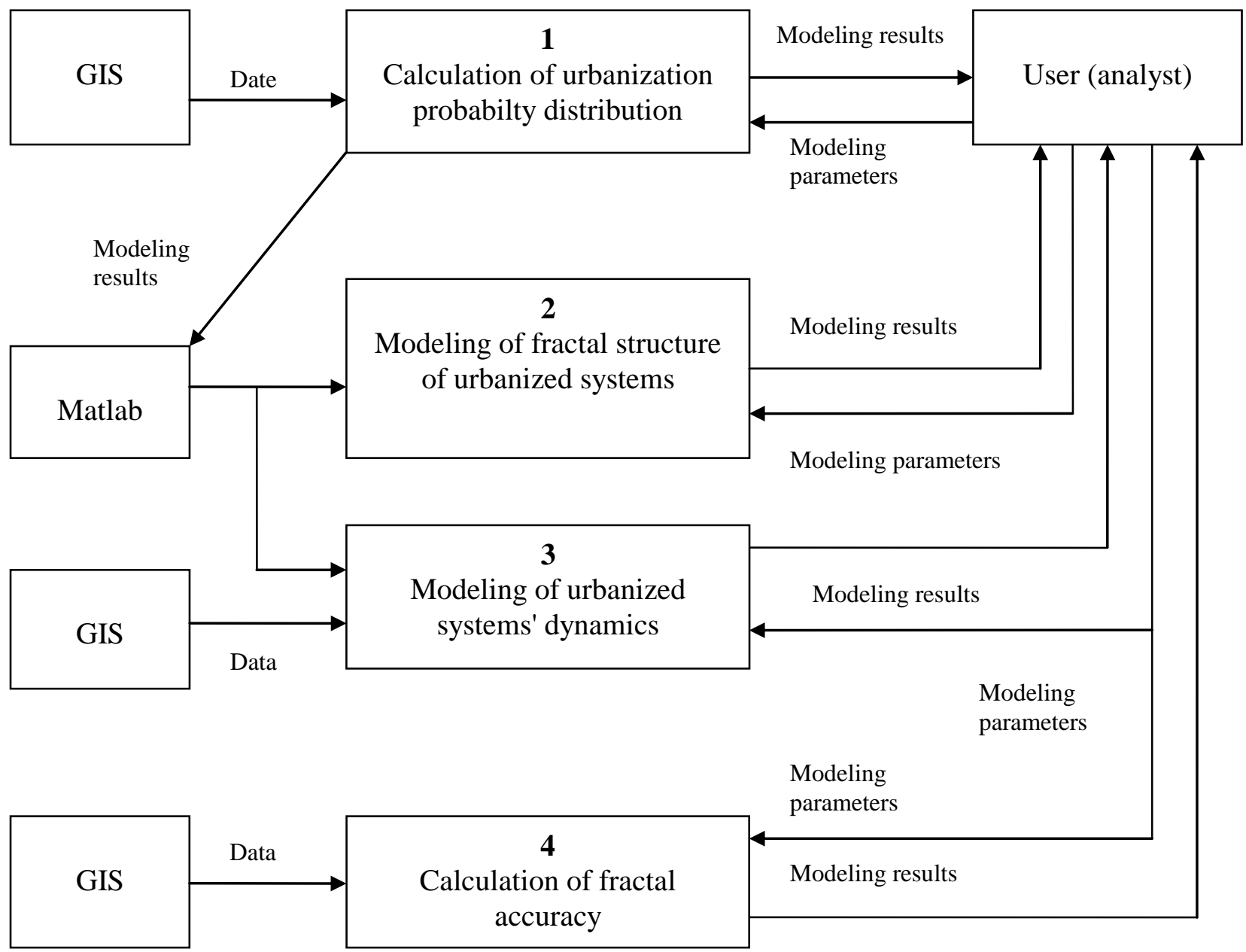

Fig. 2: IS data flow diagram.

Graphic programming interface shows the IS upper level that combines automated modules of geospatial data exchange, spatial structure form building, spatial distributions of probabilities and knowledge base. The user sets modeling parameters and selects the necessary model from a list and the modeling area with GIS. The calculations are made based on the Matlab package. The modeling results are provided to the user as graphic windows.

The IS has four blocks. The first block is related to the calculation of distributions of assigning the territory to an urbanized one, the other three blocks - to the modeling of fractal structure, dynamics of tourist settlement infrastructure development and accurate calculation.

Automated communication of IS and GIS ensures the effective use of geospatial data and employs the features of GIS to achieve the specified objectives. As information in GIS is constantly updated, IS automatically gains the capacity to work with up-to-date data. Processing the data in Matlab adds IS functionality because GIS built-in toolkit is far worse than the mathematical package in terms of its features. The proposed IS can address the remaining problems identified by the experts in the tourism industry and become a tool for scientifically grounded decision-making in strategic planning.

\section{Published By:}




\section{Service Sector and Information Technologies: Development of New Opportunities}

\section{CONCLUSION}

Information and the tourism market should respond to the needs of all categories of consumers who want to receive travel service. The state, in turn, should support and promote the development of both the traditional tourism companies targeting the customers that prefer personal communication when purchasing the services and the firms, which can meet the customer needs by using the Internet technologies.

As a result of the expert survey and analysis of scientific literature, the current state of program-methodological tools and information support of the tourism industry has been analyzed. The software in tourism has been summarized and categorized. The analysis has shown that there are enough software products to automate the operation of travel firms, registration and booking systems. However, there is no specialized software for forecasting tourism infrastructure development.

Out of many remaining tasks, the development of the automation methods should be prioritized. On this ground, an IS that integrates mathematical modeling methods and tools for the tourism industry infrastructure should be created. An IS structure has been proposed. It has been shown that the mandatory components include GIS, knowledge base, automated software module with several mathematical models for tourism infrastructure forecasting, as well as a module for building spatial distributions of assigning the territory to an urbanized one. The IS flowchart has been built.

\section{REFERENCES}

1. Global trends of world tourism. Available: https://hotelier.pro/tourizm/item/3119-unwto

2. A.B. Antonova, "Interactive information technologies as a key trend of the tourism industry development", Bulletin of the National Academy of Tourism, 3(39), 2016, pp.15-19.

3. I. Haque, A. Rahman, "Information Technology in Information Technology in the tourism industry - What More Needed?", International Journal of Engineering Sciences Paradigms and Researches, 1(1), 2012, pp. 111-117.

4. D. Geneletti, D. Dawa, "Environmental impact assessment of mountain tourism in developing regions: A study in Ladakh, Indian Himalaya", Environmental Impact Assessment Review, 29, 2009, pp. 229-242.

5. J.A. Silberman, P.W. Rees, "Reinventing mountain settlements: A GIS model for identifying possible ski towns in the U.S. Rocky Mountains", Applied Geography, 30, 2010, pp. 36-49.

6. A.N. Ludin, A.-N. Matori, K.W. Yusof, L.U. Dano, I.A. Chandio, “A spatial decision support system (SDSS) for sustainable tourism planning in Johor Ramsar sites, Malaysia Mansir Aminu”, Environmental Earth Sciences, 2012, pp. 23. Berlin, Heidelberg.

7. C.H. Tsai, W.C. Wang, C.W. Chen, H.L. Chen, M.L. Lin, "The Construction of Decision Model for Tourism Disaster Evacuation Based on GIS and Fuzzy Theory", World Academy of Science, Engineering and Technology, 54, 2009, pp. 81-85.

8. Y. Farsari, P. Prastacos, "GIS applications in the planning and management of tourism", A Companion to Tourism: Blackwell Companions to Geography. Oxford: Blackwell Publishing, 2004, pp. 596-607.

9. K.W. Wöber, "Information Supplyin Tourism Management by Marketing Decision Support Systems", Tourism Management, 24, 2003, pp. 241-255.

10. D. Roberto, "Information and Communication Technologies for Travel \&Tourism”, LTSN Hospitality, Leisure, Sport \&Tourism, 2003, pp. $1-19$.

11. R. White, G. Engelen, "High-resolution integrated modeling of the spatial dynamics of urban and regional systems", Computers, Environment and Urban Systems, 24, 2000, 24, 383-400.

12. D. McAdam, "The value and scope of Geographical Information Systems in tourism Management", Journal of Sustainable Tourism, 7, 1999, pp. 77-92
13. V. Jovanovic, "The application of Geographic information system and its Components in Tourism", Yugoslav Journal of Operations Research, 18, 2008, pp. 261-272.

14. A.G. Polyakova, M.P. Loginov, A.I. Serebrennikova, E.I. Thalassinos, "Design of a socio-economic processes monitoring system based on network analysis and big data", International Journal of Economics and Business Administration, 7(1), 2019, pp. 130-139.

15. R.A. Brymer, "Hospitality management. An introduction to the industry", Moscow: Aspect Press, 1995, pp. 326. 